\title{
Design of the Hospital Integrated Information Management System Based on Cloud Platform

\author{
L Aijing ${ }^{1,2}$, Y Jin ${ }^{3,4}$
}

\begin{abstract}
At present, the outdated information management style cannot meet the needs of hospital management, and has become the bottleneck of hospital's management and development. In order to improve the integrated management of information, hospitals have increased their investment in integrated information management systems. On account of the lack of reasonable and scientific design, some hospital integrated information management systems have common problems, such as unfriendly interface, poor portability and maintainability, low security and efficiency, lack of interactivity and information sharing. To solve the problem, this paper carries out the research and design of a hospital information management system based on cloud platform, which can realize the optimized integration of hospital information resources and save money.
\end{abstract}

Keywords: Cloud platform, hospital, information technology, management

\section{Diseño de un Sistema Integrado para el Manejo de la Información Hospitalaria Basado en la Plataforma en la Nube

\author{
L Aijing ${ }^{1,2}, \mathrm{Y} \mathrm{Jin}^{3,4}$
}

\begin{abstract}
RESUMEN
En la actualidad, el estilo obsoleto de manejo de la información no puede satisfacer las necesidades de gestión hospitalaria, y se ha convertido en un cuello de botella para la gestión y el desarrollo de los hospitales. Con el fin de mejorar el manejo integrado de la información, los hospitales han incrementado su inversión en sistemas de manejo integrado de la información. Debido a la falta de un diseño científico y razonable, algunos sistemas integrados de manejo de la información hospitalaria tienen problemas comunes, tales como interfaz poco amistosa, pobre portabilidad y mantenibilidad, baja seguridad y eficiencia, falta de interactividad e intercambio de información. Para resolver el problema, este trabajo lleva a cabo la investigación y el diseño de un sistema de manejo de la información hospitalaria basado en plataforma en la nube (Cloud), que puede realizar la integración optimizada de los recursos de información del hospital y ahorrar dinero.
\end{abstract}

Palabras claves: Plataforma en la nube, hospital, tecnología de la información, manejo

West Indian Med J 2015; 64 (5): 521

\section{INTRODUCTION}

At present, the outdated information management level cannot meet the need of the hospital management, and has become

From: ${ }^{1}$ The 3rd Xiangya Hospital of Central South University, Changsha, Hunan, China, ${ }^{2}$ Key Laboratory of Medical Information Research (Central South University), College of Hunan Province, Changsha, Hunan, China, ${ }^{3} \mathrm{Xi}-$ angYa School of Public Health (Central South University), Changsha, Hunan, China and ${ }^{4}$ XiDian University, Xi'an City, Shaanxi Province, China.

Correspondence: Y Jin, XiangYa School of Public Health (Central South University), Kaifu District, Changsha, Hunan, Lane 238 on Ma Yuanling, Changsha, Hunan 410078, China; and XiDian University, 2 South Taibai Road, Hi-Tech Development Zone, Xi'an City, Shaanxi Province 710071, China. Email: jyin@xidian.edu.cn the bottleneck of the hospital management and development. In order to improve the level in integrated management information, hospitals have increased their investment in the hospital integrated information management system [HIIMS] (2). However, on account of the lack of reasonable and scientific design, these HIIMSs have some common problems, such as unfriendly interface, poor portability and maintainability, low security and efficiency, lack of interactivity and information sharing. All of these constrain their performance advantages, and restrict the development of hospital integrated management information (3). 
The cloud platform technology is considered a technical revolution in the information technology (IT) industry, and it has become an important direction in the future development of the IT industry (4). Meanwhile, governments have considered the services based on the cloud platform as the new development opportunities of the software industry. With the help of the cloud platform, we can reduce the investment in the self-built database and improve the scalability and maintainability of the system. When the cloud platform is used to construct HIIMS, it can highly integrate and make the best of all kinds of hospital information resources, and establish the virtual application service pool, virtual storage pool, virtual network pool, virtual safety pool and virtual resource pool on the basis of unified standards, which can improve the utilization of the servers, the availability and reliability of the system, dispersive and out-of-order data storages, data security and information management (5). Therefore, this paper carries out the research and design of a hospital integrated information management system based on cloud platform (HIIMSBCP).

\section{USE CASE ANALYSIS}

According to the interviews, investigation and related materials collected, it is clear that the hospital integrated information management involves the management of the outpatient department, inpatient department, dispensary, medical technicians, query and statistics and the management of the auxiliary diagnosis. Therefore, the top use case diagram of the designed HIIMSBCP is shown in Fig. 1. Each part of the use case diagram is discussed in the following sub-sections.

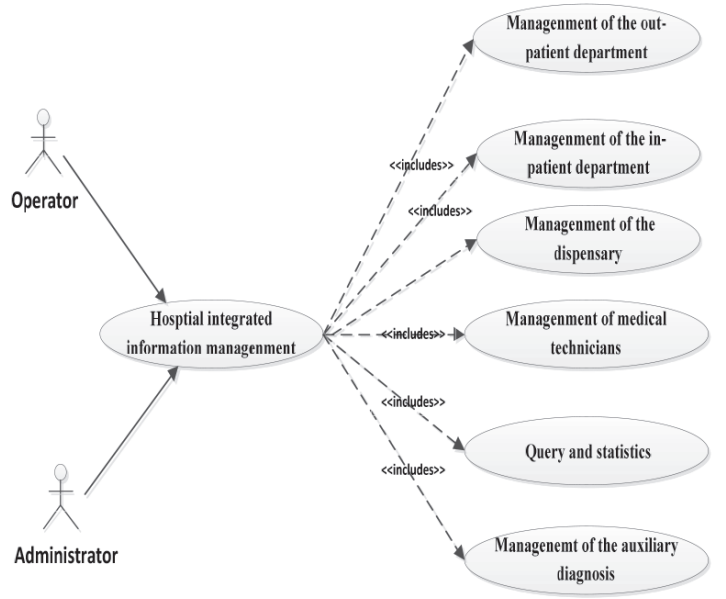

Fig. 1: Top use case diagram of the hospital integrated information management system based on cloud platform.

\section{Outpatient department}

The main work of the outpatient department is to provide medical care for the outpatient and includes management of the outpatient registration, outpatient service charge and the outpatient doctor workstation (Fig. 2).

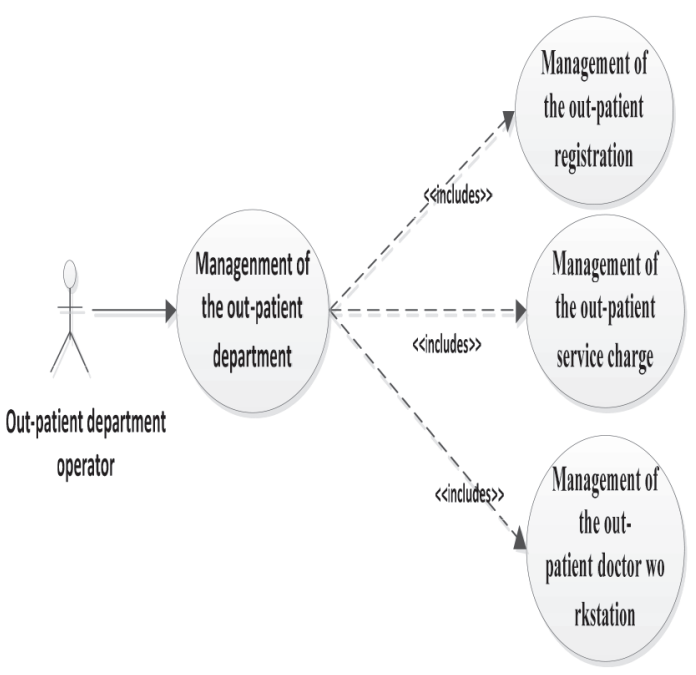

Fig. 2: Use case diagram of the outpatient department.

Figure 3 demonstrates the functional requirements of the management of the outpatient registration, which include:

- Different methods of registering, such as live registration, registration by phone and Internet, and charging the confirmed registration.

- Choice of registered department and doctor, and transmission of the information of the registered patient to the corresponding doctor.

- Supporting the use of medicare cards, and giving some privileges according to related policies.

- Querying and displaying the registered information based on the query criteria.

- Modifying and cancelling registered information.

- Exporting search results.

- Querying patients' history of registered records.

- Withdrawing registration.

- Providing print services.

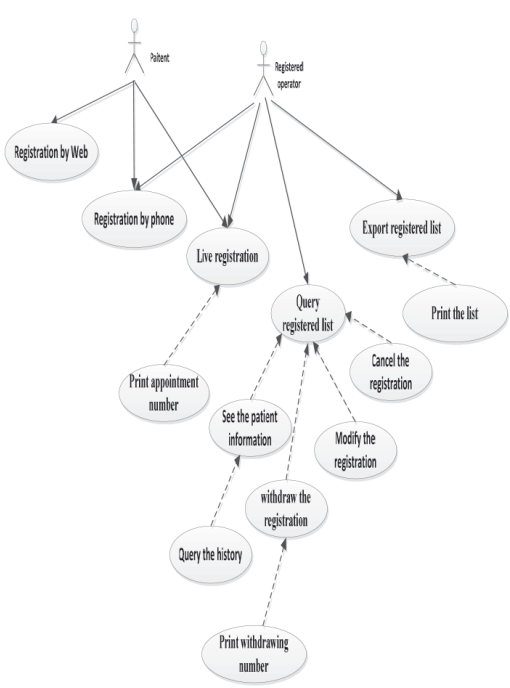

Fig. 3: Use case diagram of the management of the outpatient registration. 
The functional requirements of the management of the outpatient doctor workstation are shown in Fig. 4 and include:

- Showing the doctor the patients who registered with him, as well as the case list.

- Providing information on the current registered patient.

- Allowing the doctor to fill in electronic prescriptions, which can be saved and sent to the outpatient dispensary and outpatient charge department. The doctor can also view and cancel the prescriptions that he prescribed.

- Allowing the doctor to fill in the examination application form for the patients and transmit the related data to the outpatient dispensary and outpatient charge department.

- Querying and showing patients' prescription record history.

- Print services.

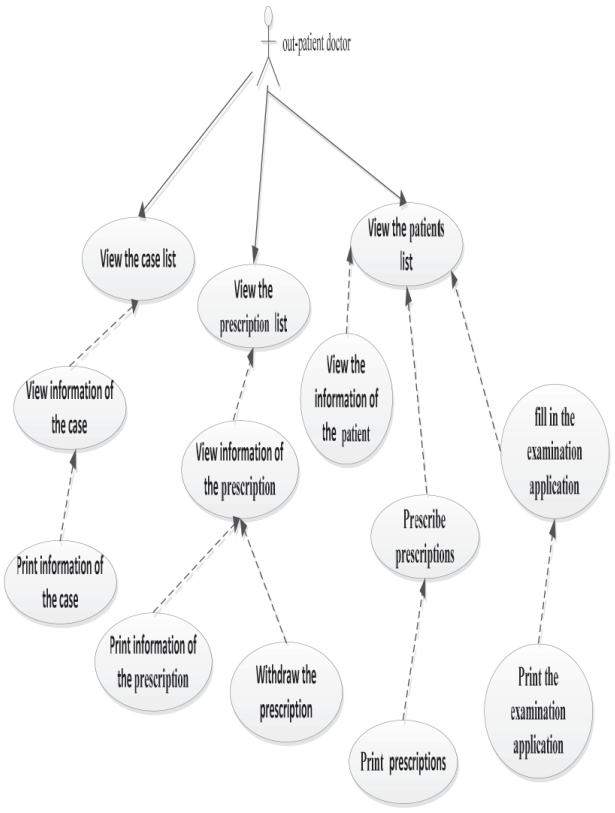

Fig. 4: Use case diagram of the management of the outpatient doctor workstation.

The functional requirements of the management of the outpatient service charge, as shown in Fig. 5, include:

- Querying and displaying the prescription list and their charge results.

- Displaying detailed information on the prescription.

- Querying and displaying the examination application list and their charge results.

- Displaying detailed information on the examination application form.

- Automatically calculating the fees of the examination application form and prescription, and transmitting the charge information to the medical technician workstation.
- Querying and providing information on the side effects and contraindications on the basis of related conditions.

- Print services.

- Providing daily settlement service.

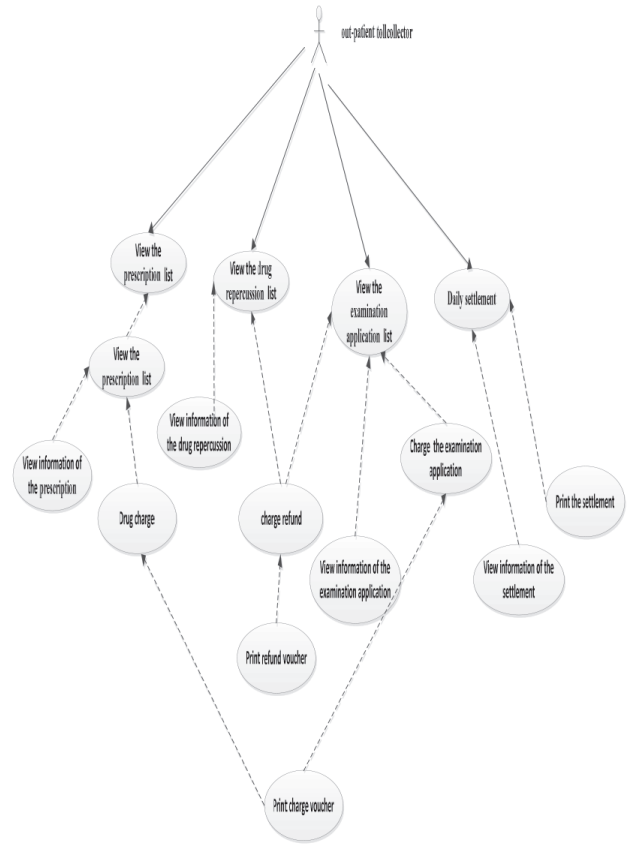

Fig. 5: Use case diagram of the management of the outpatient service charge.

\section{Inpatient department}

The main work of the inpatient department is to provide medical care for the inpatient. The process includes the management of the hospital's register, hospitalization charges, nurse workstation and doctor workstation.

The functional requirements of the management of the hospital's register include:

- Providing hospitalization services, and recording the related patient and hospitalization information, and transmitting this information to the nurse workstation.

- Querying and displaying detailed hospitalization information on the basis of the query conditions.

- Displaying the history of hospitalization records.

- Providing pre-payment service when the patient handles hospital registration.

- Providing discharge services when the patients go through the discharge formalities.

- Providing print service on the hospitalization.

The functional requirements of the management of the hospitalization charges include:

- Viewing basic information on outpatients.

- Querying and displaying the list of hospitalized patients and the balance on the account.

- Providing the pay service for the hospitalization and putting this on the patient's account. 
- Providing daily settlement service for the hospitalization and filing charge information.

- Sharing information on the prescriptions and examination application forms.

- Automatically sending reminder when the money on the account is less than the default value.

The functional requirements of the management of the nurse workstation allow the nurse to:

- Share information on hospitalized patients, doctor's advice and payment.

- Manage sickbeds.

- Display the list of sickbeds and basic information on the sickbeds.

- Query hospitalized patients in her charge according to query conditions such as the doctor's advice, treatment plans and so on.

- Record medicine-using records.

- Print.

- Record patients' conditions on the basis of the visits.

The functional requirements of the management of the hospital doctor's workstation allow the doctor to:

- Share information on hospitalized patients, doctor's advice and payment.

- Query the hospitalized patients in his charge, according to the query conditions.

- Fill in electronic prescriptions, which can be saved and sent to the outpatient dispensary and outpatient charge department.

- Fill in the examination application form for the patients and send the related data to the outpatient dispensary and outpatient charge department.

- Display history records, which include the list of the doctor's advices, electronic prescriptions and examination results.

- Print.

\section{Dispensary}

The main work of the dispensary is to provide medicine services for the patient. Generally, the hospital has three kinds of dispensaries: outpatient dispensary, inpatient dispensary and the medical storeroom. The outpatient dispensary mainly provides medicine services for the outpatient, the inpatient dispensary mainly provides for the inpatient and the medical storeroom stores the finished medicines, semi-finished medicines and medicinal materials. Semi-finished medicines and medicinal materials must first be made into finished medicines by the hospital preparation room, after which they are available to both dispensaries.

\section{Medical technician}

After the patient pays for the examination application form, the medical technician needs to provide the corresponding examination service. Moreover, the medical technician is responsible for the management of the examination results.
The functional requirements of the management of the examination include:

- Sharing information about the examination application form and payment conditions.

- Querying the list of the examination application.

- Providing file service.

The functional requirements of the management of the examination results include:

- Displaying the list of the examination.

- Displaying the examination results.

- Providing print service.

- Transmitting the examination results to the responsible doctor.

\section{Query and statistics}

The query and statistics function provides query and statistical services. Through the query service, the administrator can view the financial data of the outpatient department, the inpatient department and the dispensary. Through the statistical service, the administrator can statistically analyse the income and expenditures of every department.

\section{SYSTEM DESIGN}

Because HIIMSBCP is based on the cloud platform, the network of the topology is shown in Fig. 6.

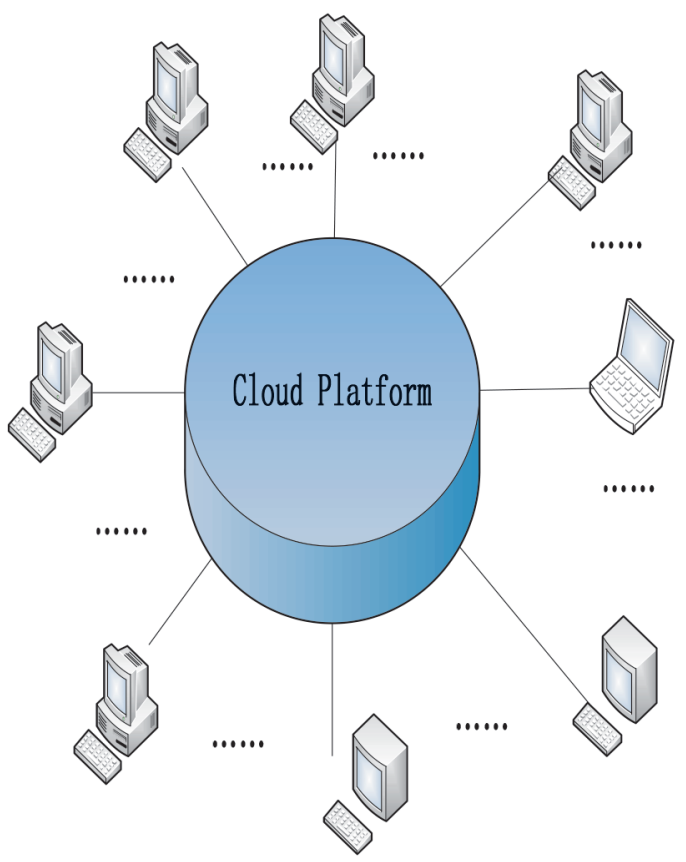

Fig. 6: Network topology of hospital integrated information management system based on cloud platform.

Every department user can log in and use HIIMSBCP by a terminal, which is connected to the cloud platform. The physical structure of the cloud platform is shown in Fig. 7.

The cloud platform consists of servers, switches, routers, firewalls and memory. And the cloud platform can provide storage, security, application and access services. 


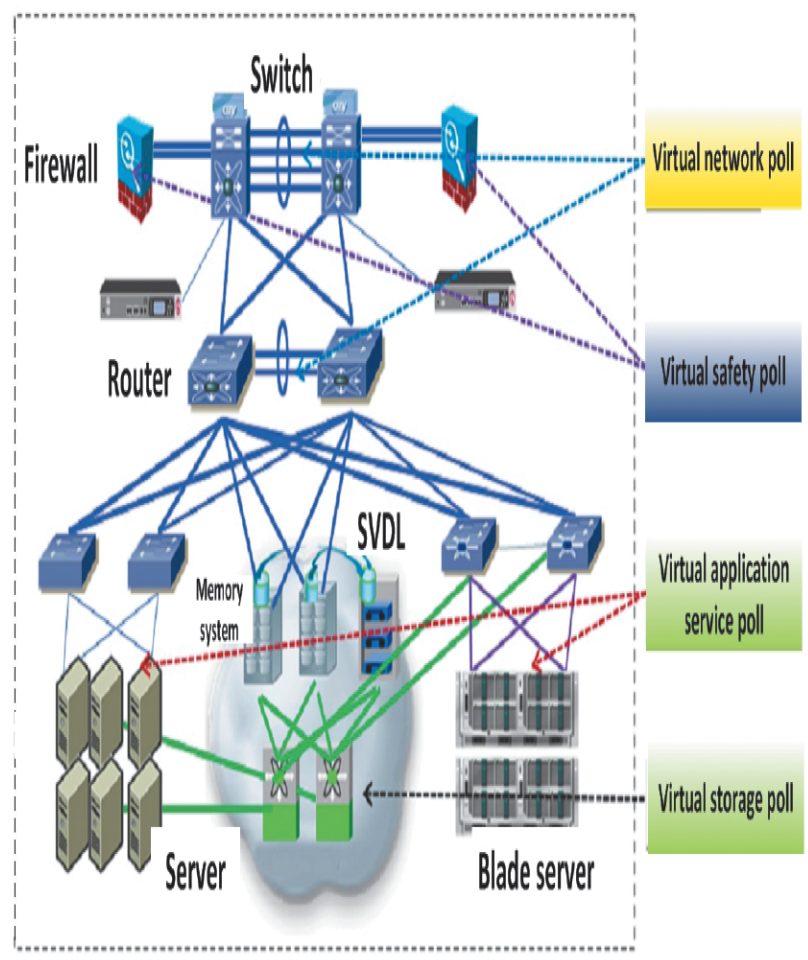

Fig. 7: Physical structure of the cloud platform.

\section{FUNCTIONAL DESIGN}

As mentioned previously, the HIIMSBCP has five subsystems: outpatient department, inpatient department, dispensary, medical technician, and query and statistics (Fig. 8). The workflows of the five subsystems are displayed in Figs. 9-12.

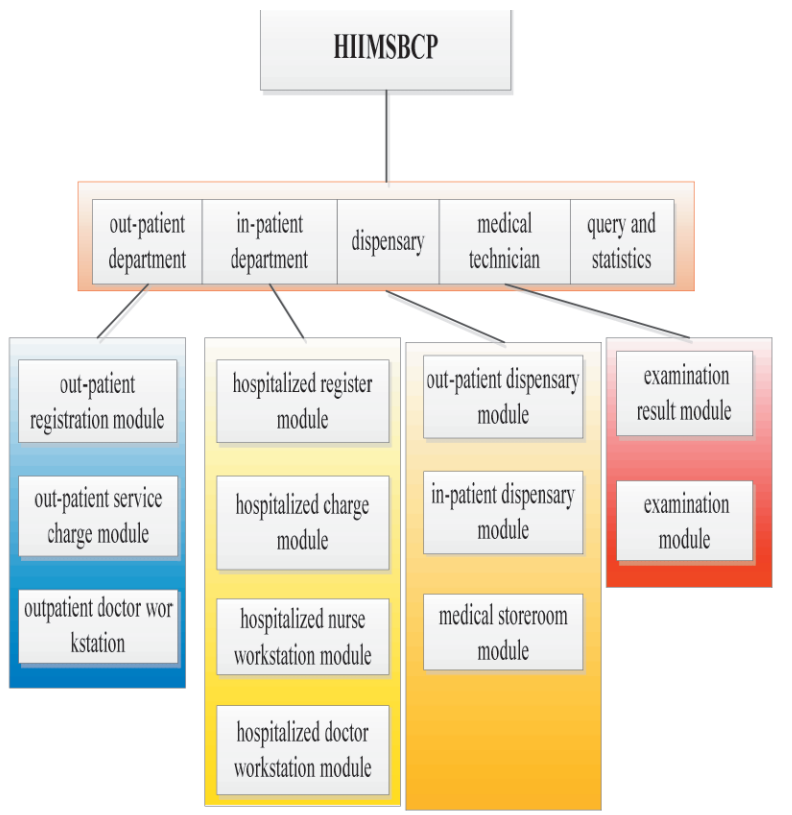

Fig. 8: Functional modules of hospital integrated information management system based on cloud platform (HIIMSBCP).

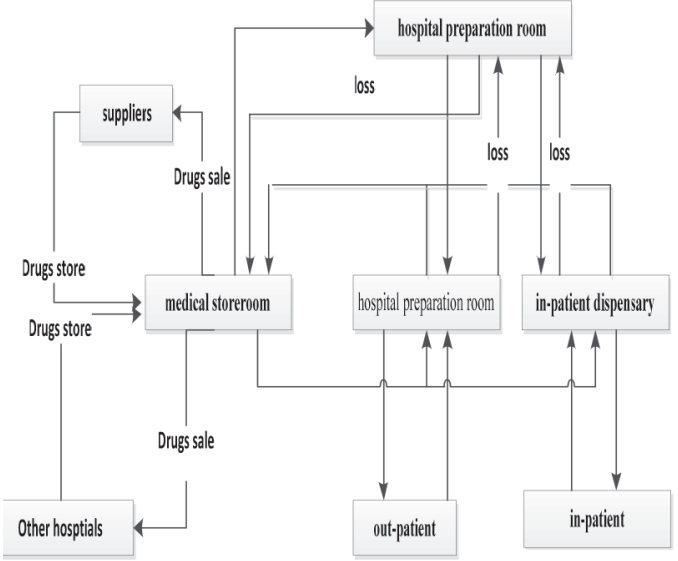

Fig. 9: Workflow of the dispensary subsystem.

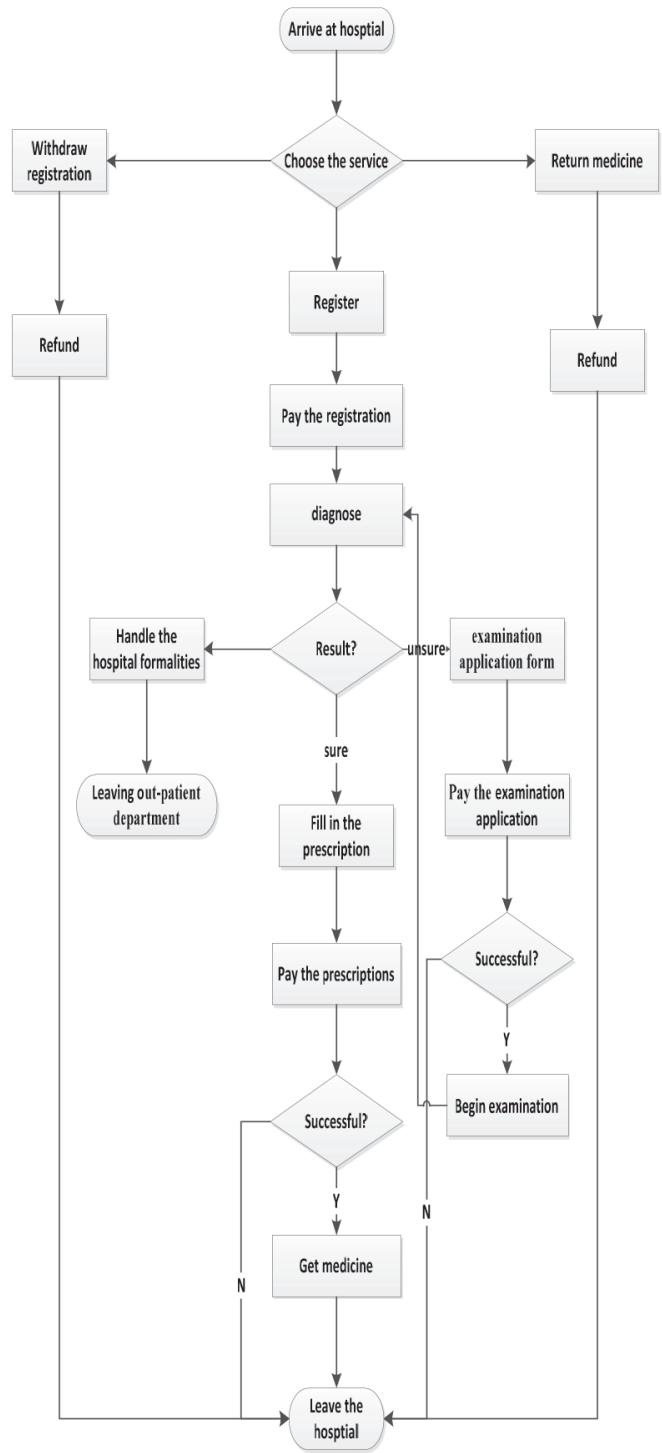

Fig. 10: Workflow of the outpatient department subsystem. 


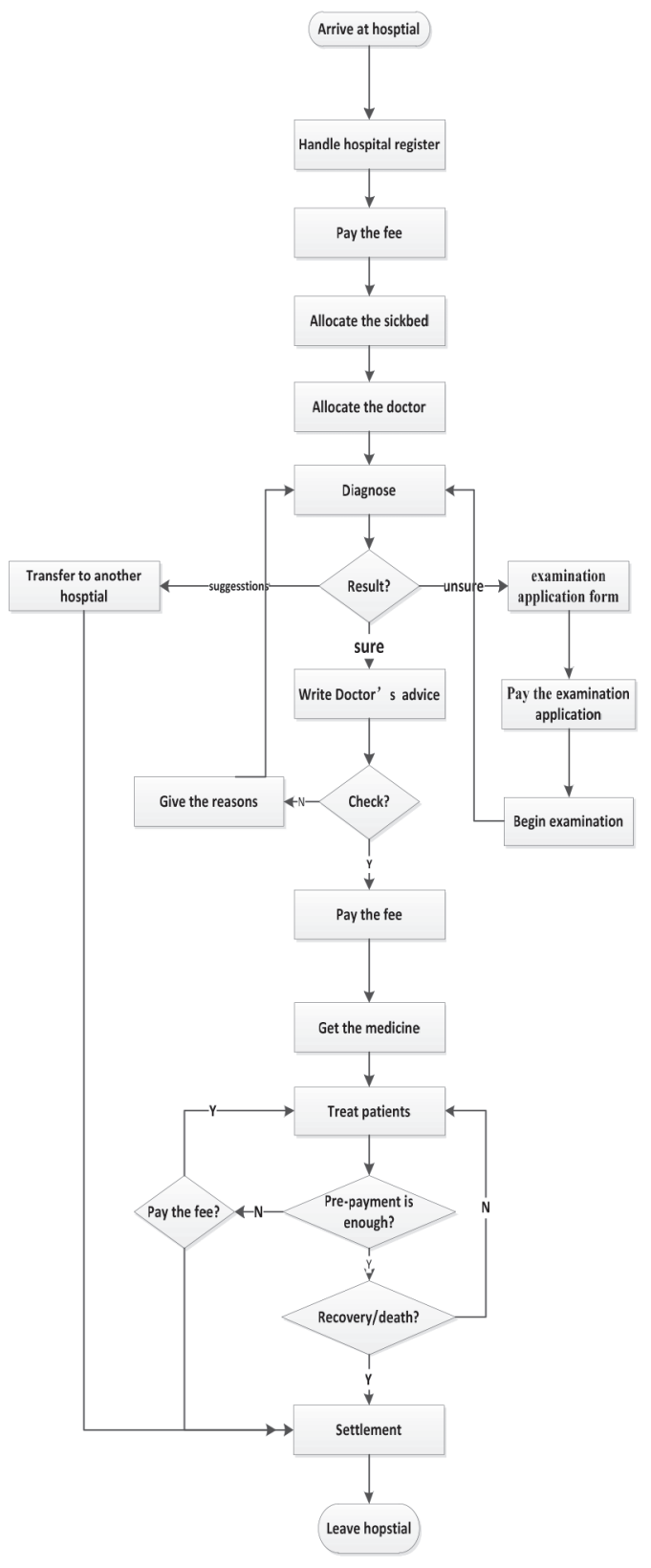

Fig. 11: Workflow of the inpatient department subsystem.

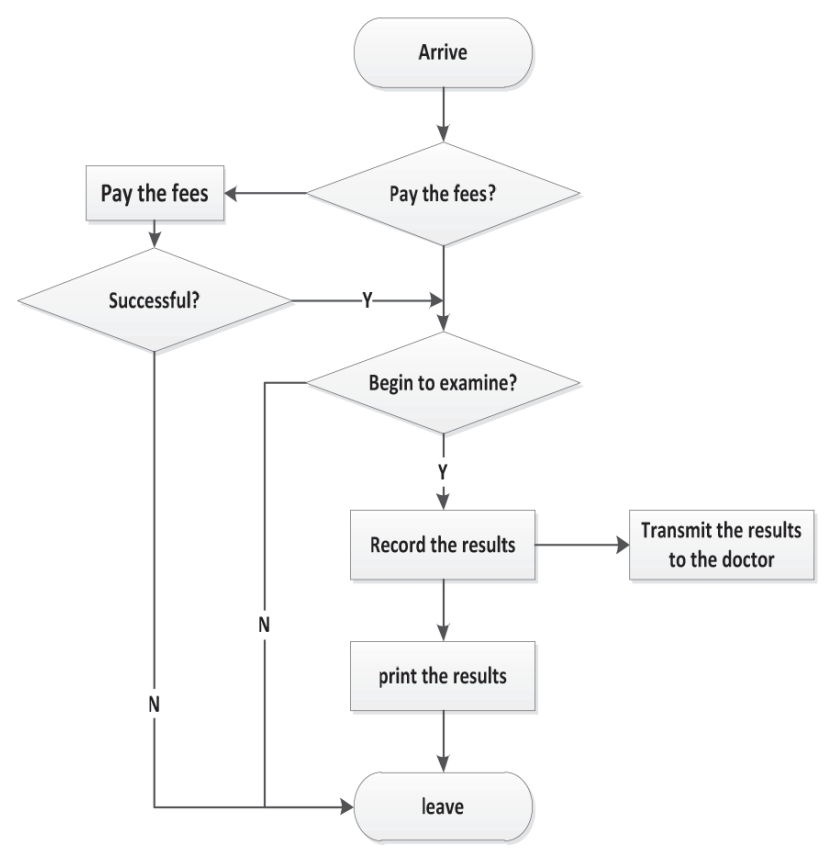

Fig. 12: Workflow of the medical technician subsystem.

\section{CONCLUSION}

The hospital integrated information management system based on cloud platform is custom-made for the hospital. It does not only realize the optimized integration of hospital information resources, but also improves the level of standardized management. Additionally, the use of the cloud platform reduces the hospital investment on hardware and software.

\section{ACKNOWLEDGEMENT}

This work was supported by the National Science Foundation of Hunan Province, China (11JJ6070).

\section{REFERENCES}

1. Reinhold H. Strategic information management in hospitals: an introduction to hospital information systems. New York: Springer Press; 2011.

2. Guoqing H, Ying Y. Integrative management of information resources of enterprises. J China Society Sci Tech Info 2012; 1: 100-7.

3. Nabovati E, Vakili-Arki H, Eslami S, Khajouei R. Usability evaluation of laboratory and radiology information systems integrated into a hospital information system. J Med Sys 2014; 38: 1-7.

4. He C, Fan X, Li Y. Toward ubiquitous healthcare services with a novel efficient cloud platform. IEEE Trans Biomed Eng 2013; 60: 230-4.

5. Aleem A, Ryan Sprott C. Let me in the cloud: analysis of the benefit and risk assessment of cloud platform. J Financ Crime 2012; 20: 6-24. 